\title{
MIGRACIONES Y FRONTERAS
}

Omar Luis Velasco ${ }^{1}$

La problemática de las migraciones fronterizas en Sudamérica reconoce una serie de factores que, más allá de los que podemos considerar contemporáneamente, se han desarrollado a lo largo de la historia de nuestro continente. Histórica, geográfica y socialmente, los mismos han contribuido en gran medida a establecer una serie de patrones de comportamiento de sus habitantes que pueden justificar la lógica de este tipo de movimientos poblacionales.

Lelio Mármora ${ }^{2}$ opina que los procesos de integración regional que se verifican contemporáneamente, representan en realidad intentos de reintegración a Unidades Políticas pre existentes. En Sudamérica, imperios precolombinos como el de los Chibchas o los Incas, al igual que la Conquista Europea, establecieron unidades administrativas y políticas que superan los actuales límites jurídicos de los Estados Americanos contemporáneos.

En dichas jurisdicciones se establecieron relaciones políticas, económicas, comerciales, sociales, familiares y aún personales, mantenidas por sistemas de comunicación, caminos y transportes establecidos a tal fin, que facilitaban el intercambio y las migraciones laborales de tipo golondrina. También deben mencionarse los movimientos compulsivos de población para su utilización como mano de obra, así como para reducir presiones demográficas, verificados antes y después de la llegada de los europeos. En el imaginario colectivo de nuestros pueblos esta territorialidad extendida se mantiene vigente a pesar que sobre la misma se superpusieron los actuales estados sudamericanos.

Por otra parte muchos de los actuales límites y fronteras nacionales se establecieron arbitrariamente, fruto de resolución de variados conflictos, separando regiones que comparten similares situaciones geográficas, climáticas

1 Delegación Corrientes de la Dirección Nacional de Migraciones, Corrientes, Argentina.

2 MÁRMORA, Lelio. Políticas de Migraciones Internacionales. Buenos Aires: Paidos, 2002. 
y productivas, por no mencionar históricas, culturales, poblacionales y aún de parentesco. Tanto estas situaciones, como las mencionadas previamente, resultan condiciones necesarias para la génesis de los actuales procesos de migraciones fronterizas internacionales.

A su vez, la existencia de condiciones suficientes, tales como factores de expulsión y de atracción en las regiones involucradas, junto a la permeabilidad en la mayoría de sus fronteras, favorecen este tipo de movimientos de población. A contrario sensu, las lógicas de las sedes administrativas centralizadas, lejos de intentar canalizar y/o administrar estos procesos, se han enfocado tradicionalmente en la ejecución de políticas restrictivas al libre tránsito de las personas, basadas primordialmente en diferentes categorías de admisión de los extranjeros, orientadas según criterios de permanencia, sea ésta transitoria, temporaria o permanente, que suponen la exigencia y cumplimiento de determinadas condiciones.

Por otra parte, entre la legislación migratoria de los países de la región, existen marcadas diferencias respecto a los criterios utilizados para categorizar el ingreso de migrantes fronterizos, sea que éstos se instalen en la, o las, localidades de frontera, o se dirijan hacia el interior del país de recepción. Argentina y el Paraguay admiten el Tránsito Vecinal Fronterizo por 72 horas, de los ciudadanos que habitan en la localidad extranjera vecina al paso de ingreso habilitado, no así a los que se domicilian fuera de la misma, los que deberán ser admitidos bajo otras categorías. Brasil, por su parte admite ingresantes en sus localidades de frontera, sin restricciones, salvo que se dirijan al interior del país, debiendo entonces ser categorizados según criterios de admisión. Chile, en su frontera con el Perú, admite el ingreso de ciudadanos que viven en la localidad de Tacna por el lapso de una semana, siempre que no abandonen el ejido de Arica.

En casi todos los países, el ingreso como tránsito fronterizo no habilita para realizar tareas remuneradas ni estudios (sólo Brasil permite la realización de tareas y estudios, inclusive universitarios, en sus localidades fronterizas a los habitantes de localidades extranjeras vecinas a las mismas). Desde su implementación, el MERCOSUR ha dictado una serie de normas sobre la temática migratoria fronteriza buscando establecer criterios comunes para el tratamiento de estos movimientos. Sin embargo, y hasta el establecimiento pleno como miembros del mismo de los hasta hoy países asociados, las normas MERCOSUR tienen vigencia sólo para Argentina, Brasil, Paraguay y el Uruguay. En 1998, un estudio sobre "Equilibrio Poblacional", ejecutado por la OIM y financiado por el Ministerio de RR.EE: de Argentina y el PNUD, que abarcó la dinámica social y laboral entre las 
localidades de Posadas (ARG) y Encarnación (PAR $)^{3}$, propuso la creación de una categoría de admisión de "residente fronterizo", válida para ambas localidades.

Asimismo, algunas localidades fronterizas entre Brasil y Uruguay han adoptado el libre tránsito entre los vecinos de las mismas, donde normalmente, la problemática fronteriza se circunscribe a los temas vinculados con el comercio fronterizo y al libre tránsito de personas entre las localidades involucradas. Con relación al primero de estos temas, existen posturas contrapuestas entre los países de la región, originadas en las diferencias de precios y salarios entre los mismos, situación que se comprueba cotidianamente en la mayoría de las fronteras existentes.

Por su parte, la cuestión del libre tránsito intrafronterizo de personas no se limita solamente a las visitas personales o familiares o de recreación y turismo, sino que se plantea e involucra en los mercados sociales de trabajo, la educación y la salud. Efectivamente, estas cuestiones requieren un tratamiento que reconozca la especificidad de la problemática fronteriza, no asimilable con la concepción aceptada tradicionalmente para la evaluación de las migraciones de país a país.

Las sociedades fronterizas son las principales afectadas por la problemática de la inmigración que reciben. Tanto sus trabajos, como sus hospitales y escuelas, reciben un impacto que modifica su fisonomía humana, social y económica. También, y con la incorporación progresiva de los migrantes a la vida societaria, los mismos comienzan a jugar un importante rol en la política local y provincial o estadual. La posibilidad de oportunidades en estos ámbitos se encuentra, generalmente, acompañada de actitudes de aceptación o rechazo de parte de los habitantes locales, basadas en una constelación de experiencias históricas, culturales, económicas y sociales, que inciden en la problemática de la inclusión social de los migrantes fronterizos.

En este sentido, es importante destacar el aporte teórico realizado por investigadores ${ }^{4}$ de la cuestión fronteriza, al incorporar conceptos como los de "región compartida" y el de "sociedad fronteriza", para una mejor aproximación a la comprensión de este tipo de fenómeno social, como lo son las migraciones fronterizas. Los mismos intentan reflejar y describir con mayor precisión las características geográficas, históricas, culturales, sociales y políticas que comparten las poblaciones localizadas en los límites jurídicos, administrativos y políticos de los países involucrados.

3 Coordinador General: Lic. Omar Luis Velasco.

4 Cf. OIM. Equilibrio Poblacional entre las localidades de Posadas (ARG) y Encarnación (PAR). 1998. 
Las experiencias e investigaciones encaradas por la OIM en algunas de las fronteras sudamericanas ${ }^{5}$, así como la participación en numerosos foros y cursos relacionados con esa problemática, han puesto de manifiesto ciertas características que fundamentan la necesidad de un tratamiento que rescate la particularidad de las situaciones que enfrentan las localidades allí situadas:

- En general se trata de localizaciones marginales en términos geográficos, económicos e institucionales en relación a los centros de decisión de sus países.

- Comparten problemas, necesidades y aspiraciones con sus vecinos de allende las fronteras.

- Se reconocen más cercanos culturalmente con esos vecinos que con sus nacionales del resto de su país.

- Usualmente, si se trata del mismo idioma, lo hablan con los mismos giros, entonación y musicalidad que sus vecinos. En el caso de diferentes idiomas, desarrollan una lengua franca (p.ej.: portuñol).

- Usan indistintamente la moneda de los países involucrados.

Estas características diferencian a las regiones fronterizas del resto de las de sus respectivos países, acentuando sus coincidencias en detrimento de sus diferencias. De todas maneras, éstas existen, y no pocas veces son las disparadoras de prejuicios negativos relativos a sus vecinos fronterizos, situación que se vería reforzada en aquéllas circunstancias en que los centros de decisión y poder centrales se encuentran relativamente cercanos geográfica y políticamente, acentuando su vocación soberana y etnocentrista.

A partir de lo precedente, se propone analizar estos procesos con el objetivo de generar experiencias que puedan ser generalizadas en la búsqueda del libre tránsito de personas en el MERCOSUR. Como aporte a dicha tarea, se propone como ejemplo de análisis de la situación de la integración social en áreas fronterizas el siguiente Proyecto.

\section{Fronteras en el MERCOSUR}

\section{1 - Antecedentes}

Las nuevas condiciones que se han instalado en la región a partir de la concreción del Mercado Común del Cono Sur, están planteando la necesidad de profundizar una serie de temas íntimamente vinculados con su futuro. Entre ellos, y no el de menor importancia, la problemática de los espacios fronterizos, y el desafío de su plena integración sociocultural. En efecto, el proceso de integración

5 Cf. OIM. Tránsito Vecinal y Comercio Fronterizo de Argentina con Bolivia, Brasil, Chile y Uruguay. 2003. 
que se verifica entre los países del Mercosur, aparece como una respuesta a la globalización, entendiendo a esta no solo como la generalización de un modo histórico de producción, sino como un proceso civilizatorio, el cual, lejos de ser homogéneo, presenta mas diferencias que uniformidades. Es que, a la par de las importantes transformaciones económicas, políticas, sociales, culturales e ideológicas, asistimos también al acrecentamiento de desigualdades regionales y a conflictos de diversa índole disparados por la constitución de mercados integrados como, como el caso de la UE, el MERCOSUR y el NAFTA.

En las palabras de Octavio lanni,

El desarrollo del modo capitalista de producción, tanto en forma extensiva como intensiva, adquiere otro impulso, basado en nuevas tecnologías, creación de nuevos productos, recreación de la división internacional del trabajo y la mundialización de los mercados. Las fuerzas productivas básicas, incluyendo el capital, la tecnología, la fuerza de trabajo y la división internacional del trabajo, sobrepasan fronteras geográficas, históricas y culturales, multiplicando así sus formas de articulación y contradicción. Es ese un proceso simultáneamente civilizatorio, ya que desafía, rompe, subordina, mutila, destruye o procrea otras formas sociales de vida $y$ trabajo, incluyendo modos de ser, pensar, hacer, sentir e imaginar ${ }^{6}$.

Por otra parte, la interdependencia, la internalización de la economía y la globalización de los problemas han modificado los ejes de la toma de decisiones, pasando de lo nacional y/o binacional, a escenarios de negociación, coordinación y cooperación regionales y/o mundiales, multilaterales. Estos esfuerzos, centrados alrededor del intercambio de bienes, capitales, tecnologías y servicios, han comenzado a considerar la problemática del tránsito de personas y, particularmente, el del intercambio de la población trabajadora. El reciente tratamiento del tema incluye, entre otras consideraciones, el reconocimiento de la preexistencia de los movimientos poblacionales transfronterizos a la consolidación de los Estados Nacionales, y aun después de élla, como anticipatorios a la formulación de los procesos contemporáneos de integración social, cultural y económica.

Sin embargo, el escenario en que tales procesos se manifiestan en la actualidad, puede definirse como contradictorio entre sus causas, características y consecuencias, y las lógicas burocrático - administrativas con que se pretende gobernarlos. Los avances y retrocesos que el proceso de integración del MERCOSUR ha venido soportando en los últimos años, fruto de sus mismas contradicciones, han colocado al mismo en los primeros planos de la opinión publica y diversos sectores sociales y económicos comienzan a expresar sus

${ }_{6}$ IANNI, Octávio. Globalización y Diversidad; PATARRA, Neide (org.). Migrações internacionais: herança XX, agenda XXI. Campinas: FNUAP, 1996, p. 1-16. 
posiciones, muchas veces contrapuestas, frente a la complejidad creciente de los problemas involucrados. Una de las cuestiones que mayores controversias genera es la relativa a las migraciones intramercosur, en tanto vehículo de la integración en términos sociales, culturales, económicos y laborales, así como parte inherente al proceso de relación entre población y desarrollo.

En efecto, por un lado, los países parte todavía no han considerado en sus políticas la incorporación de esta cuestión en sus reglamentaciones, de manera que el tránsito internacional de personas, cualquiera sea su nacionalidad, no ha sufrido alteración y se mantienen las restricciones habituales. Por otra parte, en alguna de las fronteras compartidas, los criterios de admisión y sus plazos presentan variaciones significativas, así como los criterios de control, por lo que la cuestión de la libre circulación de las personas, en tanto factor de producción, aparece todavía muy lejana. Al contrario, los países tradicionalmente receptores de migraciones laborales limítrofes, Argentina y Brasil, han comenzado a adoptar posturas restrictivas al respecto.

Sin embargo, los resultados obtenidos a partir de su aplicación, no han sido los esperados. Más que frenar, han contribuido al crecimiento de la ilegalidad y sus inevitables secuelas: trabajo en negro, explotación de personas, competencia desleal a la mano de obra local, etc. Estas consecuencias no queridas actúan muchas veces como disparadores de muchas de las opiniones que comienzan a concretarse en el imaginario social acerca de los efectos negativos de las migraciones, a pesar de lo que estudios objetivos están demostrando 7 .

Casi desde su inicio, el Mercosur ha desarrollado esfuerzos tendientes al tratamiento de los movimientos poblacionales intramercosur y sus impactos en los niveles local, regional y nacional, en especial a partir de las asimetrías que aún se verifican entre los Estados Parte y que actúan como disparadores de movimientos migratorios. Sin embargo, el tema no ha sido aún objeto de desarrollo suficiente y los órganos del proceso de integración continúan sus esfuerzos. Las actividades previstas en las nuevas pautas negociadoras adoptadas para estas cuestiones en la presente etapa del Mercosur, reconocen la particularidad del tema de las migraciones transfronterizas y su impacto en los procesos de integración social locales, y contemplan la necesidad de tratar en forma multisectorial/bilateral alguna de sus cuestiones. Puede afirmarse que en la base de este enfoque se encuentra la aceptación del importante papel que, como dinamizadoras del proceso de integración, juegan las áreas fronterizas, considerándolas como regiones y subregiones que comparten las mismas necesidades y aspiraciones de desarrollo integral. En este sentido, el proyecto plantea una línea de acción

MONTOYA, Silvia; PERTICARÁ, Marcela. Los Migrantes de Países Limítrofes en los Mercados de Trabajo Urbanos. Estudios, n. 75, octubre/diciembre 1995. 
coincidente con la orientación general adoptada por los Estados Parte en el marco de la estructura institucional del Mercosur.

\section{2 - La Problemática Fronteriza}

La realidad en las fronteras de los países que integran el Mercosur, presenta características que requieren respuestas que por el momento las administraciones centrales no parecen dispuestas a analizar a pesar de una problemática claramente diferenciada de la cuestión migratoria general y al reconocimiento creciente del papel que comienzan a desempeñar como áreas compartidas y espacios geográficos de integración ${ }^{8}$.

En términos conceptuales, la problemática aparece vinculada con aspectos tales como:

- Procesos históricos, sociales, económicos y culturales en la Región.

- Cambios en la concepción de la frontera.

- La existencia de una Región Compartida que supone conceptos tales como transfrontera, subregión, microregión, macroregión, intraregión, extraregión.

- Una dinámica social y laboral específica.

- La existencia de procesos de integración regional.

En efecto, las fronteras se comportan no ya como esclusas o válvulas que regulan tránsitos en función de decisiones administrativas o políticas, sino que reaccionan en forma totalmente espontanea e independiente de regulaciones burocráticas. Sus habitantes siguen comportamientos gestados aun antes de la constitución de los estados contemporáneos, reconociendo en la práctica la existencia de una realidad socioeconómica preexistente: LA SOCIEDAD FRONTERIZA 9 .

Como resultado de la existencia de esta realidad social, las poblaciones fronterizas reaccionan como una unidad ante el impacto generado por los procesos emergentes de la globalización y la regionalización, tal como se los plantea desde los centros de poder y decisión. Solo a partir de su aceptación y de las consecuencias que de ella se desprenden, los estados involucrados estarán en condiciones de implementar acciones que permitan la regulación y canalización de los movimientos transfronterizos. Para ello es necesario reconocer la

${ }_{8}$ QUIJANO, José C. Los Comité de Frontera y las relaciones fronterizas. In Problemas de la relación fronteriza entre Encarnación y Posadas (1995). Informes del Comité de Fronteras. Buenos Aires, 1996.

9 ABINZANO, Roberto Carlos. La Cultura de la Integración: Cómo y Dónde se Construye? Microprocesos en la Encrucijada de las Fronteras. 1997. 
especificidad de la problemática fronteriza frente a concepciones burocráticas imposibilitadas de captar la riqueza de las situaciones allí involucradas.

Desde esta perspectiva, cada sociedad fronteriza, aun compartiendo características generales ${ }^{10}$, pueden presentar adaptaciones propias a partir de sus condicionantes contextuales. En la Región considerada se han relevado algunos ejemplos, tanto de instituciones públicas como privadas, a partir de los cuales se intenta responder a situaciones emergentes de los procesos espontáneos en marcha en los espacios geográficos de integración, como deben comenzar a ser consideradas las fronteras del Mercosur:

- El ámbito de mayor generalidad lo constituyen las rondas CRECENEA/ CODESUL, las que, si bien circunscriptas por el momento a provincias del NEA Argentino y cuatro estados del Brasil (Rio Grande do Sul, Santa Catarina, Paraná y Mato Grosso do Sul), en la ronda de Foz do Iguaçu (BRA) realizada en mayo de 1997, se contó con la presencia de observadores del Paraguay presididos por el Ministro de Integración, ya que se lo ha invitado a integrar la organización regional, lo que se espera concretar en un futuro cercano.

- Durante 1997, Argentina y el Paraguay acordaron y lanzaron en la ciudad de Posadas, el "Programa Binacional de Desarrollo Fronterizo", con la intención de poner en acción un espacio económico compartido para: 1) Potenciar la capacidad productiva de la región; 2) Diseñar nuevas formas de complementación productiva; 3) Elaborar estrategias conjuntas de comercialización para la captación de nuevos mercados.

- Foro de Intendentes Regional: Durante 1998, tuvo lugar en la ciudad de Posadas la $17^{\mathrm{a}}$ edición de la misma, y la $1^{\text {a }}$ de Concejales, quienes durante dos días debatieron temas vinculados, tanto a los aspectos institucionales como a los de implementación de la presencia regional municipal.

- Corporación Frutihorticola Regional: Integrada por Formosa, Chaco, Corrientes y Misiones, con el Paraguay, conecta a sus mercados de concentración a través de una base de datos con sede en Corrientes. Declarada de interés provincial por las provincias argentinas participantes

- Federación Económica Brasileña-Argentina-Paraguaya (FEBAP): Nacida a partir de la asociación de las Cámaras de Comercio de las ciudades de Oberá (Misiones-ARG) y Santa Rosa (Santa Catarina-BRA), en 1992, evolucionó primero hacia una federación de empresarios de la región (FEDEBAP), para culminar en la institución actual. Su objetivo manifiesto es el incremento de la actividad económica

10 QUIJANO, op. cit. 
regional a partir del lema: "opciones abiertas y contactos fáciles".

- Red de Organizaciones Sociales: Integrada por diversos grupos representativos de sectores que se consideran "vulnerables" ante el avance de los procesos económicos desencadenados a partir de la generalización del modelo de economía de mercado en la región (incluyendoal Brasil), con sus programas de ajuste fiscal y su repercusión socioeconómica. En general representan mayoritariamente a sectores ligados al campesinado y a las actividades rurales.

\section{3 - La Integración Social en Frontera}

Como se viene describiendo, la realidad de las sociedades fronterizas excede los límites tanto jurídico-políticos como históricos de los actuales estados nacionales involucrados en el Mercosur. Sus lazos se fueron definiendo a través de sucesivos procesos o matrices socioculturales ${ }^{11}$, que les confirieron características propias. Estas, a su vez, fueron luego impactadas por los procesos de desintegración de aquellas y la creación de los estados modernos contemporáneos, incididos por un fuerte centralismo que comenzó a priorizar las necesidades metropolitanas por sobre las de sus territorios fronterizos. Tal proceso se refuerza a partir de las actuales condiciones en que la globalización se inserta en nuestros piases, generando escaso espacio para la toma de decisiones basadas en la satisfacción de necesidades locales.

En el Diagnóstico Contextual del Proyecto Equilibrio Poblacional Posadas - Encarnación ${ }^{12}$, cuyo objetivo era describir las condiciones sociales y económicas de la región motivo de este documento, se realiza una aproximación a la situación imperante en la misma, caracterizándola a partir de los siguientes elementos positivos:

- Una posición estratégica, tanto en términos geopolíticos como económicos, a partir de su papel de "bisagra" entre las zonas productivas del Paraguay y los puertos brasileños sobre el Atlántico.

- Un acelerado crecimiento poblacional a la luz de los emprendimientos hidroenergéticos y de la construcción de nexos físicos entre los países de la Región.

- Un proceso creciente de concentración urbana de la población regional.

- Un importante aumento del sector servicios, a partir de centros urbanos administrativos como los de Posadas (ARG), Foz do Iguaçu (BRA) y Ciudad del Este (PAR).

\footnotetext{
11 ABINZANO, Roberto C. Integración regional fronteriza: sectores vulnerables frente al impacto global. Políticas y acciones alternativas. Comunicación. 1995.

12 PNUD; OIM; MRIO. RR.EE. Proyecto Equilibrio Poblacional Posadas - Encarnación. 1998.
} 
- El reconocimiento de una Región que comparte historia, economía y procesos socioculturales comunes.

Pero también se han enumerado situaciones negativas tales como:

- El mantenimiento y, en algunas situaciones, el crecimiento, de las asimetrías entre las economías de los países de la Región, que complican la relación comercial fronteriza.

- La crisis de los sectores productivos ligados a las actividades agrícolas, así como las denominadas economías regionales.

- Un proceso de migración interna, íntimamente ligado a las crisis mencionadas, de importantes sectores sociales vinculados a la economía campesina, hacia los centros urbanos ya mencionados, constituidos en su mayoría por personas con bajos estándares de instrucción y capacitación laboral, que pasan a desempeñarse en la economía "informal".

Como respuesta, las sociedades fronterizas han desarrollado sus propios mecanismos para adecuarse al impacto conjunto de decisiones cuyo objetivo es imponer a las economías regionales los requerimientos centrales y globalizados. Muchos de aquéllos, en franca transgresión de disposiciones legales y burocráticas; otros, aprovechando los vacíos y contradicciones que las mismas presentan. Con independencia de las lógicas burocráticas, las sociedades fronterizas han plasmado algunos procesos de integración espontáneos en aspectos culturales, deportivos, familiares, de convivencia y, aun, económicos, educativos y de salud. Estos involucran diversos sectores y grupos sociales de las localidades envueltas: profesionales, trabajadores, comerciantes, empresarios, estudiantes, compradores, vendedores, etc., dan lugar a una tipología de usuarios de los beneficios compartidos por la situación fronteriza ${ }^{13}$.

Sin embargo, tal realidad requiere del necesario reconocimiento formal, fundamentalmente en aquellos temas vinculados a los mercados laborales, a la salud y a la educación, de manera de garantizar la plena vigencia tanto de los derechos como de las obligaciones involucradas en dichas actividades, los que, de otra manera, quedan expuestos a su sistemática violación. Sin mecanismos institucionales que los regulen, canalicen y estimulen, muchas de las actividades espontáneas de integración enfrentan diariamente distintos tipos de represión y/o exclusión, siendo encasilladas como ilícitas.

Dejadas libradas al mero juego de sus intereses emergentes, las sociedades fronterizas quedan expuestas a cíclicas recurrencias de situaciones de marginación económica, social y, no pocas veces, política, con respecto a la formulación de

13 Ibidem. 
estrategias concertadas con los respectivos poderes centrales, quienes optan por hacer prevalecer sus propios intereses. La existencia de asimetrías, las medidas restrictivas dirigidas a controlar el comercio como el trabajo intrafronterizo, son un claro ejemplo de acciones impuestas a la sociedad fronteriza.

La problemática fronteriza posee características que la convierten en un teatro de experiencias significativas en el sentido que:

- Es un espacio geográfico de integración. En el mismo se verifican multiplicidad de actividades sociales, económicas y culturales, más allá de fronteras jurídico-políticas.

- Constituye, generalmente, una sociedad fronteriza que reconoce desde orígenes, historia, cultura, geografía y actividades económicas comunes, que la recorta con características propias de otras regiones de sus respectivos países.

- Es una Región Compartida, en cuyo ámbito encierra limites internacionales, donde se verifican situaciones similares respecto de sus centros respectivos de decisión.

- Es un espacio de interacción humana, susceptible de ser analizado como unidad metodológica.

En este contexto, las situaciones fronterizas deben pasar a ser consideradas como un escenario apto para la formulación de estrategias de integración social en el marco de programas de Equilibrio Poblacional Fronterizo, donde el esfuerzo se dirija a la articulación de diagnósticos de necesidades y condicionantes con el diseño de mecanismos institucionales que estimulen, canalicen y regulen las actividades dirigidas a la concreción de objetivos concertados y compartidos, tanto por la sociedad fronteriza, como por sus respectivos centros de decisión y poder. En este sentido, se hace necesario evaluar el impacto que la toma de decisiones originadas en distintos niveles, global, regional, nacional, provoca en las fronteras y las respuestas adaptativas con que éstas intentan minimizar u optimizar tales impactos. Estas situaciones constituyen un verdadero laboratorio en espacios acotados, particularmente aptos para el análisis de aquéllos aspectos en los que ya se verifican respuestas espontáneas como lo son los temas educativos, de salud, seguridad y laborales. 